\title{
Innovation International Talents System of Shaanxi University Supporting the Construction of Belt and Road Initiative
}

\author{
Fengxiang Jiang* \\ *Business Department, Xi’an Peihua University, Xi’an, Shannxi, China 710125
}

Keywords: Shaanxi University; system thinking; international talents; "Belt and Road Initiative"

\begin{abstract}
With the promotion of Belt and Road initiative, Shaanxi occupies an important geographical advantage as the starting point of the Silk Road. In the implementation of the "Belt and Road" initiative, Shaanxi colleges and universities need to give full play to their advantages and function. In order to train talents for the national and regional exchanges between countries involved in the Belt and Road, this paper puts forward the ways and countermeasures of systematic thinking innovation and international talents training to support Shaanxi's integration into the construction of Belt and Road, using field research and interviews to obtain rich data resources, understanding Shaanxi "Belt and Road" international talent demand, building a new-brand Shaanxi international talent training ideas on the background of "Belt and Road Initiative ", to provide some reference suggestions for the construction "Belt and Road" in Shaanxi.
\end{abstract}

The Vision and Action for promoting the Construction of the Silk Road Economic Belt and the Maritime Silk Road in 21th century were officially released On March 28th 2015, explaining that the "Belt and Road" strategy has entered the substantive promotion stage, General Secretary Xi Jinping pointed out during his visit to Shaanxi that Shaanxi should find a correct position. The Shaanxi provincial government has proposed to build Shaanxi into a new starting point for the Silk Road Economic belt, but Shaanxi's plan has encountered challenges, such as "Chongqing, New Europe," and "Rong New Europe." "Han new Europe", "Zheng Xin ou" and so on have all crossed Xi'an to drive to Europe through Xinjiang, but Shaanxi's "Chang'an" only drove to Central Asia. Therefore, Shaanxi should create a new starting point of the Silk Road Economic Belt. To bring into play the traditional position and role of the Silk Road Economic Belt, it is essential to strengthen and gather its own economic strength to form a powerful radiation source. Talent is an indispensable and important force in economic development. Therefore, Shaanxi needs to make full use of the advantages of college and university resources and attach importance to the cultivation of "Belt and Road" strategic talents, taking the initiative into the "Belt and Road" pattern.

\section{Review of Research Status at Home and Abroad}

Wang Yanxin (2015) put forward the "deep Belt and Road Initiative" strategy to promote, talent is the key "in the text of " The Belt and Road "strategy to lead the internationalization of higher education" , "The Belt and Road" strategy implementation need to train a group of proficient in foreign languages, familiar with international rules, with international vision, seize opportunities and strive for the national talent initiative in global competition. Universities should combine its own characteristics and advantages of academic resources, focus and characteristics, deeply involved in the "The Belt and Road" strategy.

In the text of " Innovation System Thinking of University" The Belt and Road "International Personnel Training Path > in the text," Wen Jun, Jiang Xianling (2015) put forward the Belt and Road "strategy for internationalized talents is not only reflected in the language skills, more is reflected in the characteristics of comprehensive, complex, the traditional system of internationalization talent training of" non-system "phenomenon restricts the cultivation of internationalized talents quality; proposed the use of innovation system thinking to cultivate international talents to crack problem. Finally, the paper constructs involving" talent - cultivation process of import export growth of three basic links, the framework of talent training system in six 
aspects close contact, in order to improve the quality of training international talents, our country "The Belt and Road" strategy in the process of "soft" talent reserves.

From the existing literature, we can conclude that most of the researches mainly focus on language teaching from the perspective of a professional person or from the perspective of regional economics.

In the text "based on the research and development of human resources in Shaanxi Belt and Road Initiative", Yan Yujie, Xie Jiaojiao (2015) put forwards that Shaanxi is as a new starting point for Silk Road Economic Belt, the bridgehead of the western development and in China hinterland connections China Eastern, central and north-west, an important geographical location in the southwest region, the development of the research of human resource exploitation in Shaanxi is particularly important. Shaanxi should establish the talent resource, to create a favorable environment for talent development; the concept of cultivating innovative talents, according to the needs of the market positioning; relying on the advantage industry, steadily to enhance the talent development effectiveness; to improve the talent the market system, to create a good system conditions for the rational flow of talent; talent development to increase fiscal support; people-oriented, establishing an effective incentive system to attract. And retain talents, adjust the structure of talents, and make the adjustment of talent structure and economic structure optimization together.

Zhang Baotong (2015) put forward that Xi'an build Shaanxi into six major centers, one of which became the center of Silk Road Economic Belt science and technology education, recruit students with the Silk Road economy oriented, do Confucius college, training Silk Road Economic Belt economic and cultural personnel. From the above literature, can be summed up: the status of Shaanxi in the" The Belt and Road ", highlighting the importance of talent training, but for Shaanxi to cultivate international talents The Belt and Road" lack of systematic thinking, needs further study in the "Four Strategic Power" for the Shaanxi Belt and Road Initiative.

" The Belt and Road" strategy attracted a strong response, but because the time is not long, the theory and practice are not very mature, there is no systematic and comprehensive theoretical system and framework, lack of systematic training and innovation in most domestic and foreign research.

\section{Necessity and Needs of Shaanxi "The Belt and Road" International Talents}

In the background of "The Belt and Road" strategy, China changes into foreign powers, China for the use of foreign capital and foreign investment showed good momentum. Shaanxi as a starting point of ancient Silk Road plays an important role in promoting the "The Belt and Road construction. Shaanxi is in response to national development strategy, the development direction of the national response to deepen the reform of the personnel management system, the construction of powerful human resources based on the objectives, emphasis on international talents for promoting Shaanxi economic cooperation development mode and realize the value of the Belt and Road.

In the opportunity of "The Belt and Road", foreign capital into Shaanxi is bound to the emergence of a large number of multinational companies, and Shaanxi for foreign language majors, foreign trade talents, high-level translation talents, high-level innovative talents, technical talents, interdisciplinary talents, foreign-related legal talents, international financial personnel, logistics professionals, international innovation entrepreneurial talent such as growth in demand quantity, and requirements for the comprehensive quality of talents to enhance the quality of personnel training, also have higher requirements, not only need to receive professional training, but also need to own international business, international standards and legal awareness, and comprehensive ability of international exchange and cooperation of talents with the deepening of integration. Shaanxi Belt and Road Initiative "construction, deepening economic and trade cooperation between, will need more innovation and entrepreneurial talent. 


\section{Advantages and Obstacles of Talents Training of Shaanxi Belt and Road Initiative}

There are many colleges and universities in Shaanxi Provinces. Especially the provincial capital of Xi'an City in the territory of Shaanxi Province, there are a large number of colleges and universities concentrated, an education and cultural center of Shaanxi Province. Xi'an Jiao Tong University, Shaanxi Normal University, Xi'an International Studies University and other colleges and universities are very important for the cultivation of international talents. Shaanxi has established a research center in Poland, Arabia Culture Research Center think tank, the international exchange and to improve the level of sharing and collaborative research.

There are problems in international talent training mode in Shaanxi University, lack of talent training for no talent training target has the trend of convergence, the teaching environment is relatively simple, the teaching mode trends theoretical teaching, practical teaching effect is relatively poor, the teaching conditions are relatively backward, international exchanges opportunities lacks, paying little attention to the cultivation of cross language communication ability, the lack of ability for innovation and entrepreneurship.

\section{Study on the Path of Shaanxi into the "The Belt and Road" Construction of the Systematic Thinking of Cultivating Innovative Talents}

We will adjust and optimize the discipline and specialty settings of relevant colleges and universities in the province, and speed up the training of non-general-purpose language talents and national regional research talents that are urgently needed by the country. To promote the construction of education and training bases facing the countries along the Silk Road break the traditional pattern of running schools in Shaanxi Province break through the differences in levels and levels of development and strengthen the construction of the mechanism of joint training of talents between schools and colleges. Reduce the repeatability of specialty setting, take the specialty of each university, and train talents across schools, to satisfy "Belt and Road" talent training, for example, Russian foreign trade talents, based on the international economy and trade specialty. Foreign language proficiency enhancement can be outsourced to language colleges and universities to achieve joint training.

Master "The Belt and Road talent market demand, deepen the cultivation of personnel system reform in Shaanxi, Shaanxi in close cooperation with the social resources, to stimulate college students in Shaanxi" The Belt and Road "opportunities under the entrepreneurial opportunities in mining, cultivate more innovative talents, promote the integration of Shaanxi" The Belt and Road construction. Shaanxi can set up "area a road of innovation base", to encourage students to entrepreneurship Park, mining resources overseas students. For the countries along the Silk Road culture with practical industry and market Chinese, professional local talent, promote the international port district into the district enterprises in technology, products and resources such as "go out" and "bringing in talent innovation and entrepreneurship.

Build the network platform of "Belt and Road" talents training in Shaanxi, establish the interactive experience center of "Belt and Road" international talent training, and integrate Shaanxi into the construction of "Belt and Road" to strengthen the cultivation of talents. Build network international talent training platform, strengthen personnel training institutions and other participants in the interactive exchange. Timely and dynamic grasp of the status of talent training. Shaanxi and "Belt and Road" along the road countries and regions of the humanistic exchange platform, Shaanxi should strive to "Belt and Road" along the way to build a humanistic exchange platform. The exchange of ideas and culture promotes the exchange and interaction of Belt and Road internationalized talents for Belt and Road.

\section{Acknowledgements}

Fund Project: Education Science Planning Project of Shaanxi Province in 2017: Innovation International Talents System of Shaanxi University Supporting the Construction of Belt and Road 
Initiative (SGH17H456)

\section{References}

[1] The research group, Chinese and the maritime Silk Roadresearch center of Fujian Academy of Social Sciences Li Hongjie, Lin Xingan. "In Pingtan Belt and Road Initiative" in the construction of the status and role of [J]. research review, 2017 (1): 41-44.

[2] Xia Yijun, Pan Deng. Colleges and universities have a brilliant future in "[J]. Economic Research Guide the Belt and Road construction, 2016 (10): 66-69.

[3] Huang Weiwei. Ningxia private university development situation of [J]. management in "The Belt and Road" in the construction of observation, 2016 (18): 90-92.

[4] Hu Yan. "The Belt and Road international strategy to lead the new horizon to vigorously promote the internationalization of Sichuan private higher education [J]. Sichuan business school academic, 2016 (1): 1-3.

[5] Zou Hongyan. Lei Hongmei, Ma Ying. "The Belt and Road" strategy under the guidance of the internationalization of Higher Vocational Education -- a case study of Career Technical College economist [J], 2017 (1): 234-235.

[6] Zhoumin. Overseas Friendship Association to promote the "sensitive. The Belt and Road" in the construction of advantage and suggestions for [J]. education in Colleges and universities in Shaanxi Herald, 2016 (24): 15-16.

Profile of the Author: Fengxiang Jiang (1983.07-), female, Institution of Business, Xi'an Peihua University, Associate Professor, research interests: Regional Economics, Human Resource Management and Entrepreneurship Education 